\title{
Strength and Failure Characteristics of Natural and Water-Saturated Coal Specimens under Static and Dynamic Loads
}

\author{
Wen Wang $\left(\mathbb{D},{ }^{1,2}\right.$ Heng Wang, ${ }^{1}$ Dongyin Li $\mathbb{D}^{1,2}$ Huamin Li, ${ }^{1,2}$ and Zhumeng Liu ${ }^{1}$ \\ ${ }^{1}$ School of Energy Science and Engineering, Henan Polytechnic University, Jiaozuo 454003, China \\ ${ }^{2}$ State and Local Joint Engineering Laboratory for Gas Drainage \& Ground Control of Deep Mines, \\ Henan Polytechnic University, Jiaozuo, Henan 454003, China
}

Correspondence should be addressed to Wen Wang; wwang306@foxmail.com and Dongyin Li; lidongyin@126.com

Received 21 December 2017; Accepted 21 March 2018; Published 8 May 2018

Academic Editor: Longjun Dong

Copyright @ 2018 Wen Wang et al. This is an open access article distributed under the Creative Commons Attribution License, which permits unrestricted use, distribution, and reproduction in any medium, provided the original work is properly cited.

Rock bursts occur frequently in coal mines, and the mechanical properties of saturated coal specimens under coupled staticdynamic loading need to be studied in detail. Comparative tests of coal specimens having different water content under static and static-dynamic loading are conducted using the split Hopkinson pressure bar (SHPB) and RMT-150C test systems. The results demonstrate that the natural specimen strength is greater than that of seven-day (7D) saturated specimens under both uniaxial compression and triaxial static compression loading; however, the dynamic strength of 7D saturated specimens is lower than that of natural specimens under one-dimensional static-dynamic loading. The particle size of the 7D saturated specimens is relatively small under uniaxial static compression and one-dimensional static-dynamic loading, and the specimen particle sizes before and after static triaxial loading tests and three-dimensional static-dynamic loading tests do not exhibit an obvious difference.

\section{Introduction}

Geotechnical engineering practices, such as mining, slope stability, and water conservation, are significantly affected by water. Rocks and rock masses are multiphase composite natural mediums including a large number of pores and cracks with different scales, thereby containing a certain amount of water. In general, under saturated conditions, the presence of water has a significant effect on the physical, chemical, and mechanical properties of coal and rocks.

Microseismic monitoring can play an important role in the prediction of the rock bursts in deep mines [1-3]. As the moisture content of coal increases or decreases, the characteristics of microseismic and acoustic emissions also change. Few studies exist on the strength and failure characteristics of water-saturated coal specimens under impact, and the results of such an investigation are helpful in preventing rock burst.

The mechanical properties (namely, uniaxial compressive, tensile, and shear strengths) of saturated and dry rocks have been studied extensively under static loading. Research results demonstrate a trend whereby the quasistatic rock strength decreases following saturation [4-10]. However, the dynamic rock strength following saturation exhibits uncertainty in terms of increase and decrease. Thus far, numerous research studies have been conducted on the mechanical properties of rock under dynamic loading at different strain rates [11]. Huang et al. [12] studied the mechanical properties of saturated sandstone tensile strength under dynamic loading in SHPB system, and the results indicated that the tensile strength softening factor decreases with the loading rate. Yan and Ma [13] conducted uniaxial dynamic compression tests on sandstone under different saturation conditions, demonstrating that the dynamic strength of saturated sandstone increased by 18 to $29 \%$ compared to dry sandstone. Moreover, static and dynamic loading strength tests of sandstone under different water bearing conditions were carried out in SHPB system by Zhou et al. [14, 15], revealing that the static and dynamic sandstone strengths decreased by $29.88 \%$ and $40.55 \%$, respectively, following saturation.

Rock bursts frequently occur around roadways and working faces in coal mines [16-19]. During this process, a coal seam exists in the stress environment under medium strain 


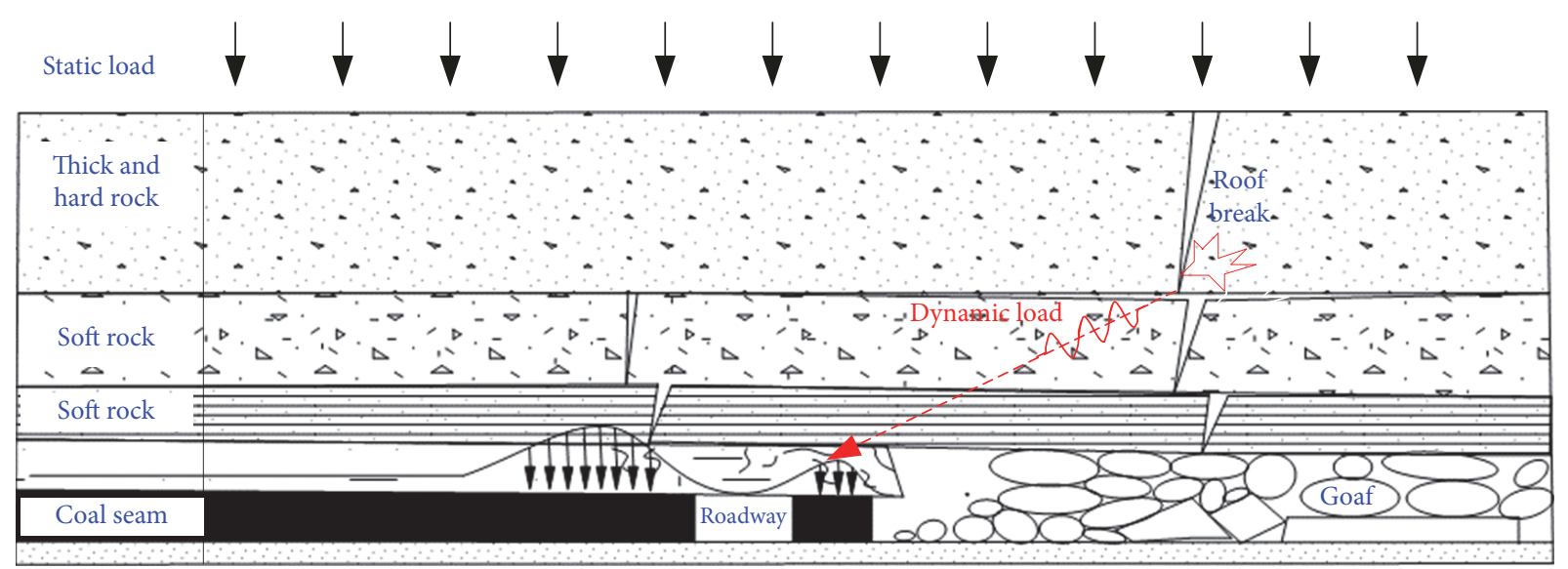

FIGURE 1: Rock burst induced by breaking of hard roof structure.

rate loading, and the coal seam failure degree can be directly affected by water content. Water injection may alleviate or prevent the occurrence of rock bursts [20, 21]. Numerous research studies have been carried out on the mechanical properties of coal specimens under static loading: Su et al. $[22,23]$ studied the effects of saturation time on the coal burst tendency index; Pan et al. [24] conducted research on the saturated time effect in the Qianqiu coal mine as well as the coal seam water injection method; and Liu et al. [25, 26] investigated the mechanical properties of water-injected coal specimens by using water injection test equipment. However, the dynamic mechanical properties of saturated coal specimens have rarely been studied.

Rock bursts with static and dynamic coupling loading frequently occur in the Yima coal mining area, Henan province, China. The thick $(80 \sim 400 \mathrm{~m})$ and hard rock roof may be broken, as shown in Figure 1, generating frequent impact loadings on coal seam under a preexisting high static load and resulting in the occurrence of rock bursts. In order to alleviate coal seam rock burst, the water injection method is used to increase the coal water content, which weakens the coal seam and thus reduces the possibility of rock burst. Therefore, the strength characteristics and damage morphology of natural and seven-day (7D) saturated specimens under both a 1D and 3D static load (static-dynamic load loading) are studied. The results provide theoretical and engineering guidance for rock burst prevention in coal mines.

\section{Experimental Work}

2.1. Specimen Preparation. Coal specimens were collected from the number 21 coal seam in the Yuejin coal mine. In order to reduce data scattering in the tests, the specimen was cut from the same working face, as shown in Figure 2. The main component of the number 21 coal seam is long flame coal, with a $\mathrm{W}^{\mathrm{f}}$ of $4.88 \%, \mathrm{H}_{\mathrm{m}}^{\mathrm{f}}$ of $4.25 \%$, and Rom of 0.505 . The specimens were $\varphi 50 \mathrm{~mm} \times 30 \mathrm{~mm}$ cylinders with nonparallelism of less than $0.05 \mathrm{~mm}$ and surface evenness of less than $0.02 \mathrm{~mm}$, in accordance with standards in the International Society for Rock Mechanics (ISRM) [27], suggested specification, as illustrated in Figure 3.

With porosity cracks and a multijoint structure inside, coal is a complicated and heterogeneous type of rock, differing from limestone, granite, and sandstone on both the macroscopic and microcosmic scale. When enlarged 200 to 500 times using the scanning electron microscope (SEM), as shown in Figure 4, the coal specimens exhibited obvious voids and clear cracks with a large opening degree, while few cracks were present in the limestone. During the test, the selected specimens were divided into two groups: coal in its natural state and that in 7D saturation (saturated in water for $168 \mathrm{~h}$ ). The water content of the specimens ranged from 3.2 to $6.1 \%$, and the porosity and the coefficient permeability were $5.83 \%$ and $0.3541 \sim 0.3849 \mathrm{~m}^{2} /\left(\mathrm{Mpa}^{2} \cdot \mathrm{d}\right)$, respectively.

To enable comparison, the specimen sizes used in the static and static-dynamic coupling tests were the same. Specimens numbered from A1 to A6, B1 to B6, C1 to C10, and D1 to D10 were used in the static uniaxial compression test, $1 \mathrm{D}$ static-dynamic loading, true triaxial static compression test, and 3D static-dynamic loading, respectively.

2.2. Testing Facilities. Static tests were conducted using the RMT-150C rock mechanism experimental system at Henan Polytechnic University, China, as shown in Figures 5(a) and 5 (b). The testing frame stiffness was $5.0 \times 10^{9} \mathrm{~N} / \mathrm{mm}$; the strain rates covered in the tests ranged from $10^{-1}$ to $10^{-6} \mathrm{~s}^{-1}$, and the maximum load was $1000 \mathrm{kN}$. The test range was $50 \mathrm{~mm}$, the maximum confining pressure was $50 \mathrm{MPa}$, and the confining pressure rate ranged from 0.001 to $1 \mathrm{MPa} / \mathrm{s}$. This system can characterize dynamic responses and obtain stressstrain curves for uniaxial and triaxial compression tests using different control methods.

Experiments under static-dynamic loading were performed using SHPB system at Central South University, China, as shown in Figures 5(c) and 5(d). The SHPB system consisted of two bars made of $40 \mathrm{Cr}$ alloy; the diameter of the bars was $50 \mathrm{~mm}$ and the elastic compression wave velocity was $5410 \mathrm{~m} / \mathrm{s}$. This system can be used for testing the 


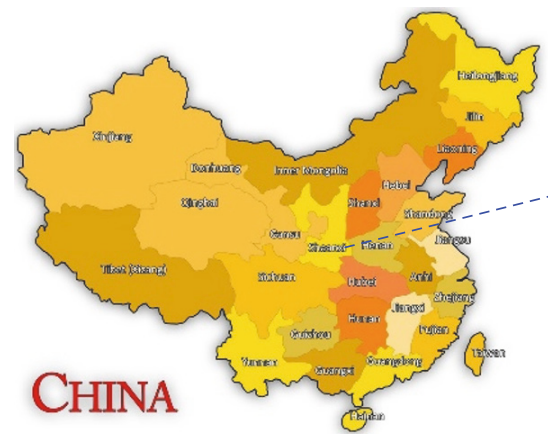

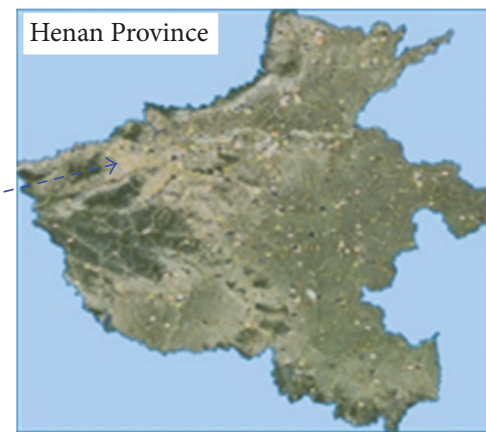

(a)

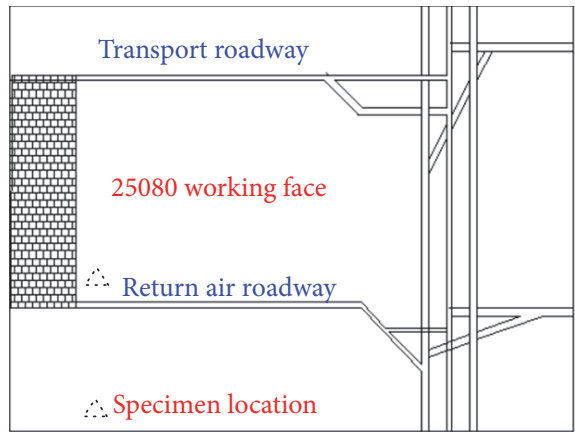

(b)

FIGURE 2: Location of Yuejin coal mine: (a) Yuejin coal mine in Henan province, China, and (b) selected specimen locations in 25080 working face.

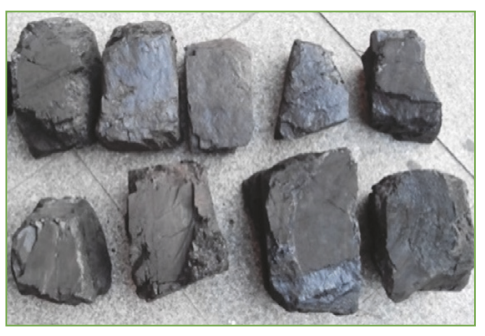

(a)

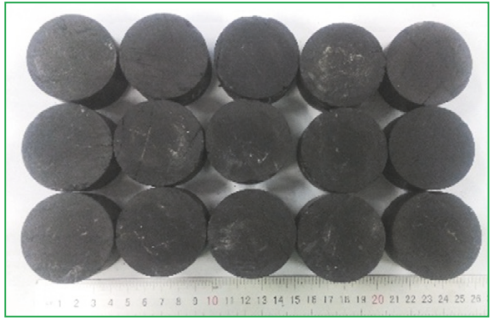

(b)

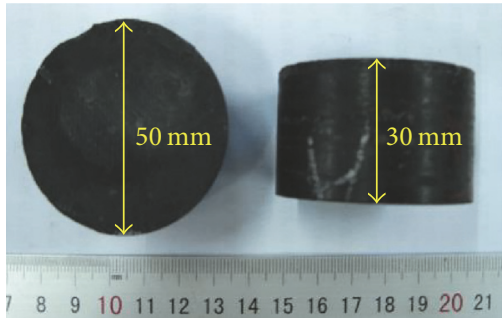

(c)

FIGURE 3: Specimens for static and dynamic testing: (a) specimens before processing and (b) specimens after processing.

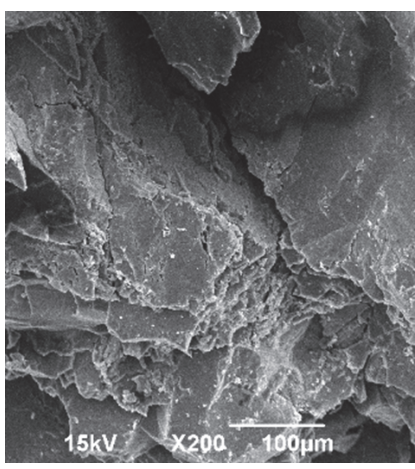

(a) Coal $\times 200$

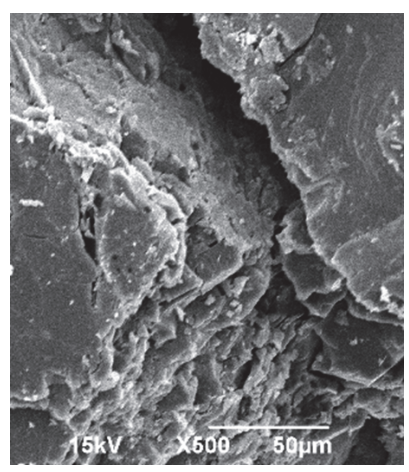

(b) $\mathrm{Coal} \times 500$

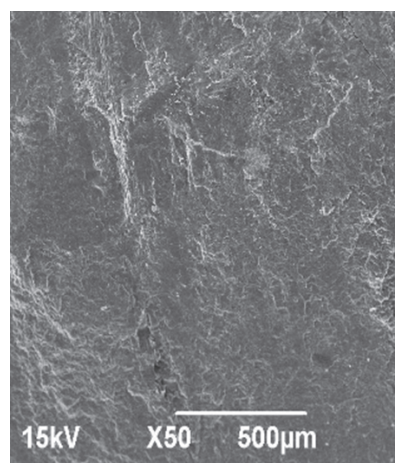

(c) Limestone $\times 50$

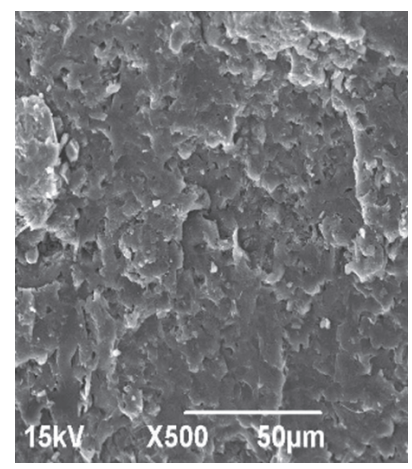

(d) Limestone $\times 500$

FIGURE 4: SEM testing photos of coal and Shendong limestone specimens.

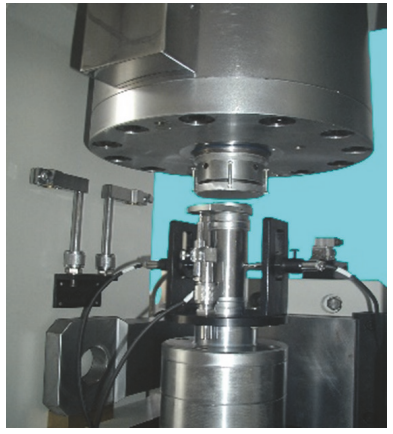

(a)

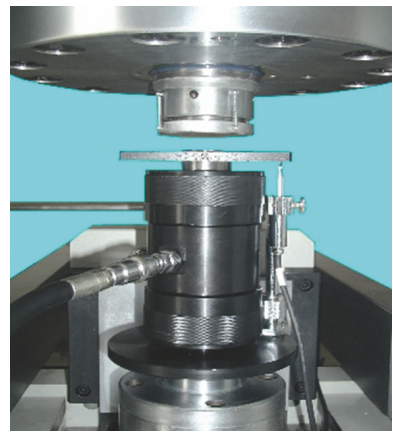

(b)

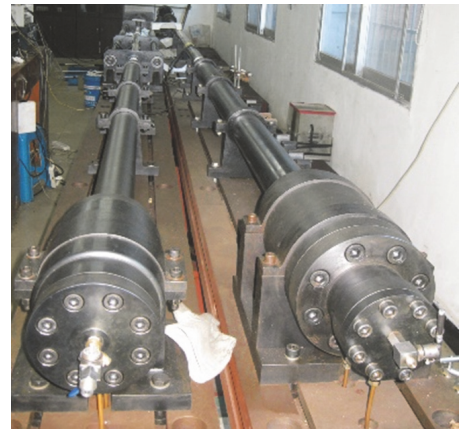

(c)

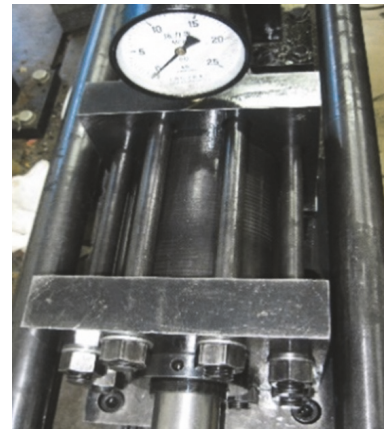

(d)

FIGURE 5: Various parts of RMT-150C and SHPB testing system: (a) uniaxial static system; (b) triaxial static system; (c) SHPB testing system; and (d) triaxial static-dynamic system. 


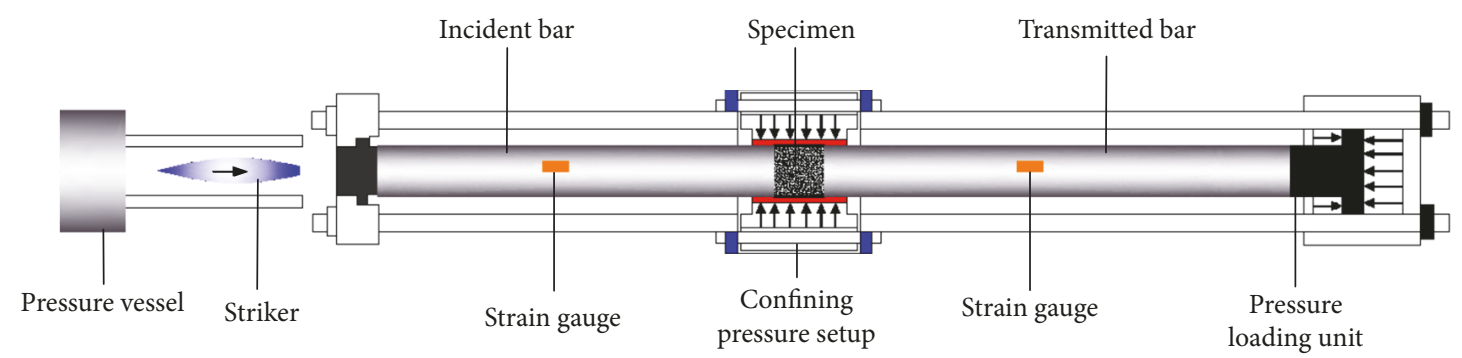

FIGURE 6: Schematic of SHPB testing system.

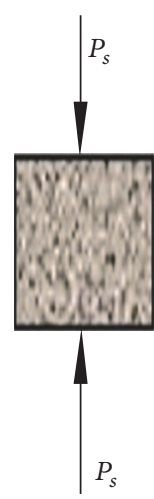

(a)

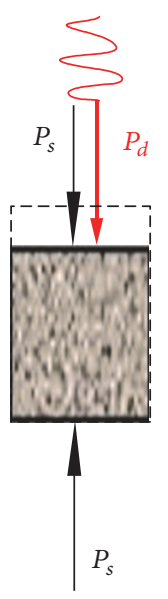

(b)

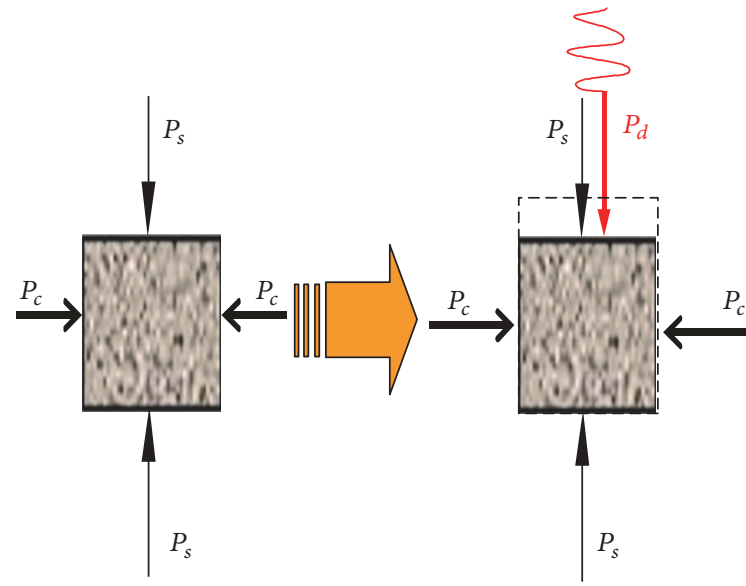

(c)

(d)

FIGURE 7: Mechanics diagrams of specimen under static and dynamic coupling loads.

dynamic properties of heterogeneous brittle materials, such as rock, concrete, and coal seams, under different confinement conditions. The axial precompression ranged from 0 to $200 \mathrm{MPa}$ the confining pressure ranged from 0 to $20 \mathrm{MPa}$, and the dynamic impact load ranged from 0 to $500 \mathrm{MPa}$. The system employs half-sine wave loading in order to reduce the waveform dispersion and achieve a constant deformation rate by using a special-shaped bullet. Further details can be found in [28].

2.3. Experimental Plans. During static compression tests, the axial deformation and the load were measured by a $5 \mathrm{~mm}$ displacement transducer and $1000 \mathrm{kN}$ compression transducer, respectively. During the experiment, axial loading was applied by means of displacement control with a loading speed of $0.002 \mathrm{~mm} / \mathrm{s}$. In the triaxial confining compression tests, the confining pressures were set as $2,4,6,8$, and $10 \mathrm{MPa}$. The natural and 7D saturated specimens were tested under uniaxial and triaxial static compression conditions, respectively.

For the static-dynamic coupling tests, 1D static-dynamic tests were conducted, where a static load of $12 \mathrm{MPa}$ was firstly imposed on the specimen prior to dynamic loading, following which dynamic loading was applied by a bullet impacting the end of the incident bar. The bullet was driven by a gas gun having 0.4 MPa gas pressure. In this manner, the strength and failure characteristics of natural and 7D saturated specimens were investigated. In the 3D static-dynamic loading tests, a confining compression of $4 \mathrm{MPa}$ and axial compression of 8 , $12,16,20(28)$, and $36 \mathrm{MPa}$ were applied to the natural and $7 \mathrm{D}$ saturated specimens in order to conduct group tests. A schematic of the SHPB testing system is provided in Figure 6. The specimen stress states under different loadings are shown in Figure 7, where (a) illustrates the specimen loading process under static uniaxial compression; (b) shows the 1D staticdynamic loading process; (c) illustrates the loading process of specimens under triaxial static compression; and (d) shows the loading process of specimens under 3D static-dynamic loading.

The SHPB tests were based on the assumption that the $1 \mathrm{D}$ elastic wave theory is applicable during stress wave propagation in the long bar. The stress, strain, and strain rate of the specimens were measured by strain gauges on the pressure bars, which can be determined by

$$
\begin{aligned}
& \sigma(t)=\frac{A_{e} E_{e}}{2 A_{s}}\left[\varepsilon_{I}(t)+\varepsilon_{R}(t)+\varepsilon_{T}(t)\right], \\
& \varepsilon(t)=\frac{C_{e}}{L_{s}} \int_{0}^{t}\left(\varepsilon_{I}(t)-\varepsilon_{R}(t)-\varepsilon_{T}(t)\right) d t, \\
& \dot{\varepsilon}(t)=\frac{C_{e}}{L_{s}}\left[\varepsilon_{I}(t)-\varepsilon_{R}(t)-\varepsilon_{T}(t)\right],
\end{aligned}
$$



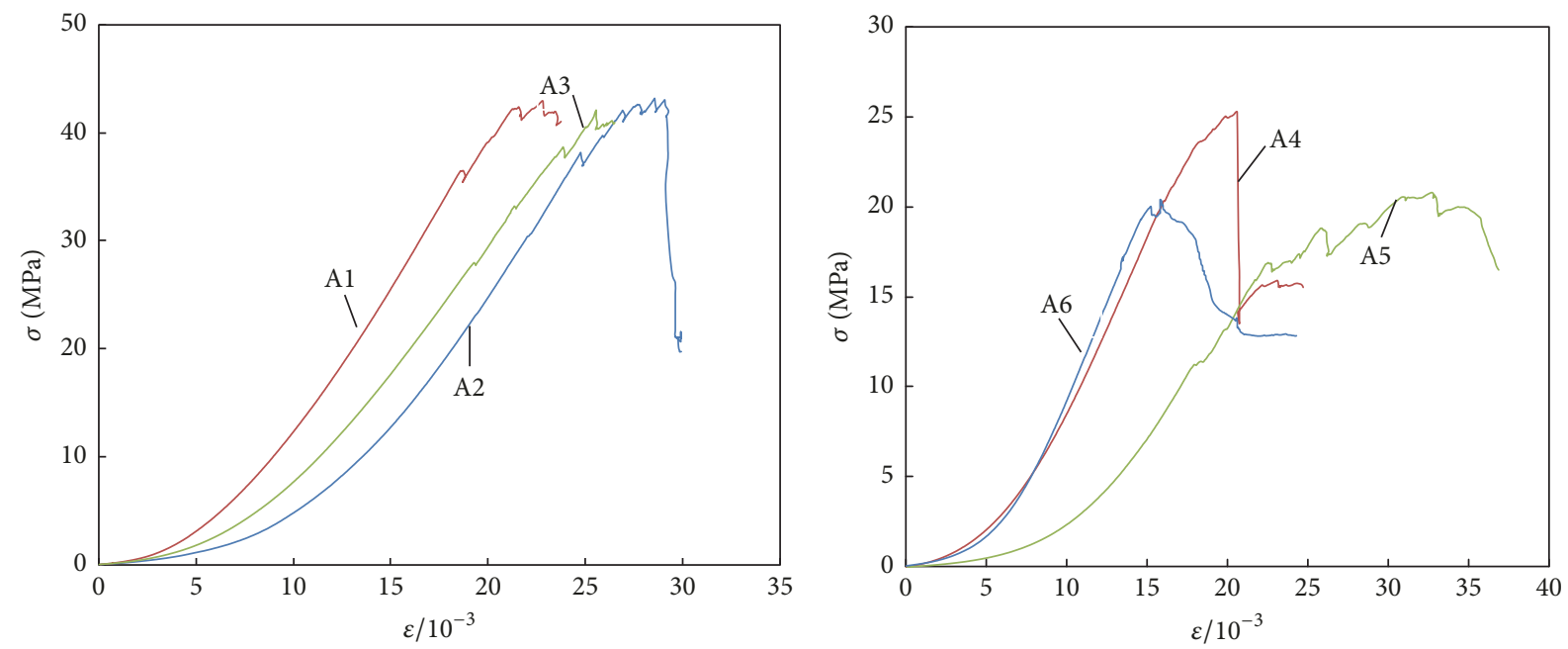

FIGURE 8: Stress-strain curves of natural and saturated coal samples under static loads.

where $A_{s}$ and $A_{e}$ are cross-sectional areas of the specimens and pressure bar, respectively; $E_{e}$ is the elastic modulus of the pressure bar; $\varepsilon_{I}, \varepsilon_{R}$, and $\varepsilon_{T}$ denote the incident, reflected, and transmitted strain waves measured on the incident and transmission bars, respectively; and $C_{e}$ and $l_{e}$ are the stress wave velocity in the bar and tested specimen length, respectively.

\section{Results and Discussion}

3.1. Results of $1 D$ Static Tests. Stress-strain curves for the natural and 7D saturated specimens under static uniaxial compression are depicted in Figure 8. The uniaxial compression strength of natural coal specimens ranges from 42.07 to $43.11 \mathrm{MPa}$, with an average of $42.71 \mathrm{MPa}$, as shown in Table 1. The uniaxial compression strength for the 7D saturated coal specimens ranges from 20.40 to $25.30 \mathrm{MPa}$, with an average of $22.17 \mathrm{MPa}$. The softening coefficient of the uniaxial compression strength between the 7D saturated and natural state ranges from 0.49 to 0.59 , and the average is 0.52 . The coal strengths exhibit certain scatterings, and the coal compression strength and elastic modulus are affected by $7 \mathrm{D}$ saturation to a certain degree, indicating a trend of decreasing strength with increasing saturation time. In general, the coefficient of rock is between 0.7 and 0.95 . As coal is sedimentary with natural multicracks, these cracks are more developed than in other rocks; therefore, the coal peak softening coefficient is higher than that of rocks.

The specimen fissure development during static compression tests can be divided into four stages, as follows: (I) Compaction stage: the microcracks are compacted, and the stress-strain curve exhibits an upward concave shape during this stage. (II) Elastic stage: the characteristics of this stage are that the microcracks continue to compact and close, while the stress-strain curve exhibits a linear increase. (III) Expansion and failure stage: primary cracks develop, and secondary cracks are induced, and the stress-strain curve exhibits a fluctuation, declining and reaching the peak value. (IV) Peak failure stage: slip failure of the specimen appears during this stage.

3.2. Results of $1 D$ Static-Dynamic Loading Tests. 1D staticdynamic loading tests were conducted on natural and 7D saturated specimens, with four specimens used in each state. The dynamic strain rate ranges from 90 to $155 \mathrm{~s}^{-1}$. Figure 9 illustrates the specimens in different saturated states.

The dynamic compression strengths of the natural specimens range from 43.47 to $46.93 \mathrm{MPa}$, with an average of $46.71 \mathrm{MPa}$, as shown in Table 2. The dynamic compression strengths of the 7D saturated specimens range from 13.50 to 40.63 MPa, with an average of 28.20 MPa. The average softening coefficient of dynamic strength between the natural and 7D saturated specimens is 0.60 . The dynamic compression strength exhibits a decreasing tendency with an increase in water content. A large difference exists between the natural and 7D saturated specimen dynamic compression strengths, and the specimen strengths in the same saturated state also exhibit scattering, indicating that coal specimens possess heterogeneous characteristics.

The compression strength of the coal specimen under both static and 1D static-dynamic loadings decreases with an increase in saturation time. Although the stress-strain curves of the natural and 7D saturated specimens under 1D staticdynamic tests exhibit a similar trend, certain differences remain in the elastic stage. The yield strength of the staticdynamic loading tests is close to that in the static loading tests. The strength of specimens under static-dynamic loading conditions is increased by 10 to $30 \%$ compared to that under static loading.

Experimental results from Wang et al. [29] demonstrate that, at a strain rate of $52-56 \mathrm{~s}^{-1}$, the saturated sandstone stress-strain curve is similar to that of natural sandstone in the uniaxial dynamic test; however, the saturated sandstone dynamic strength is higher than that of natural sandstone, which is opposite to the tendency of the saturated sandstone dynamic strength decreasing with increasing water content. 


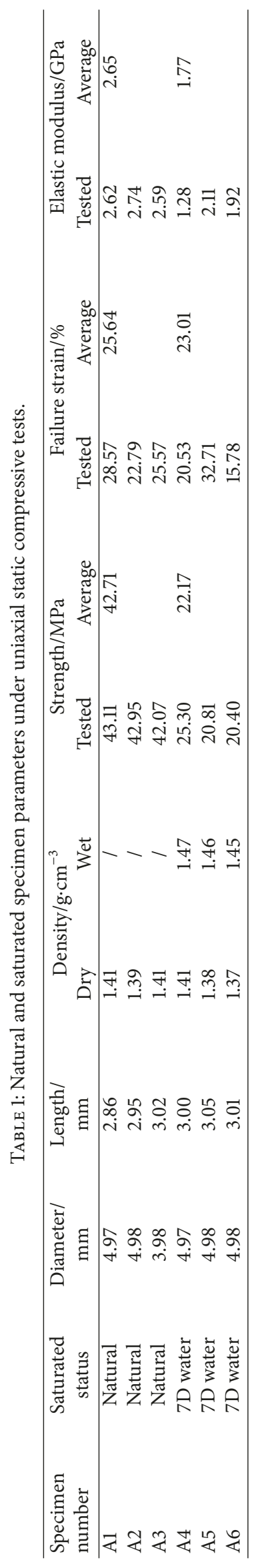




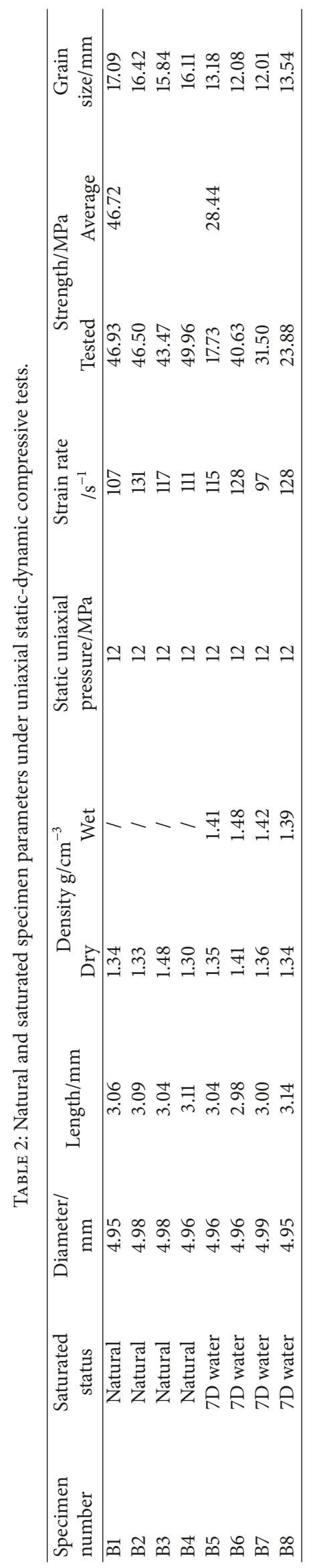



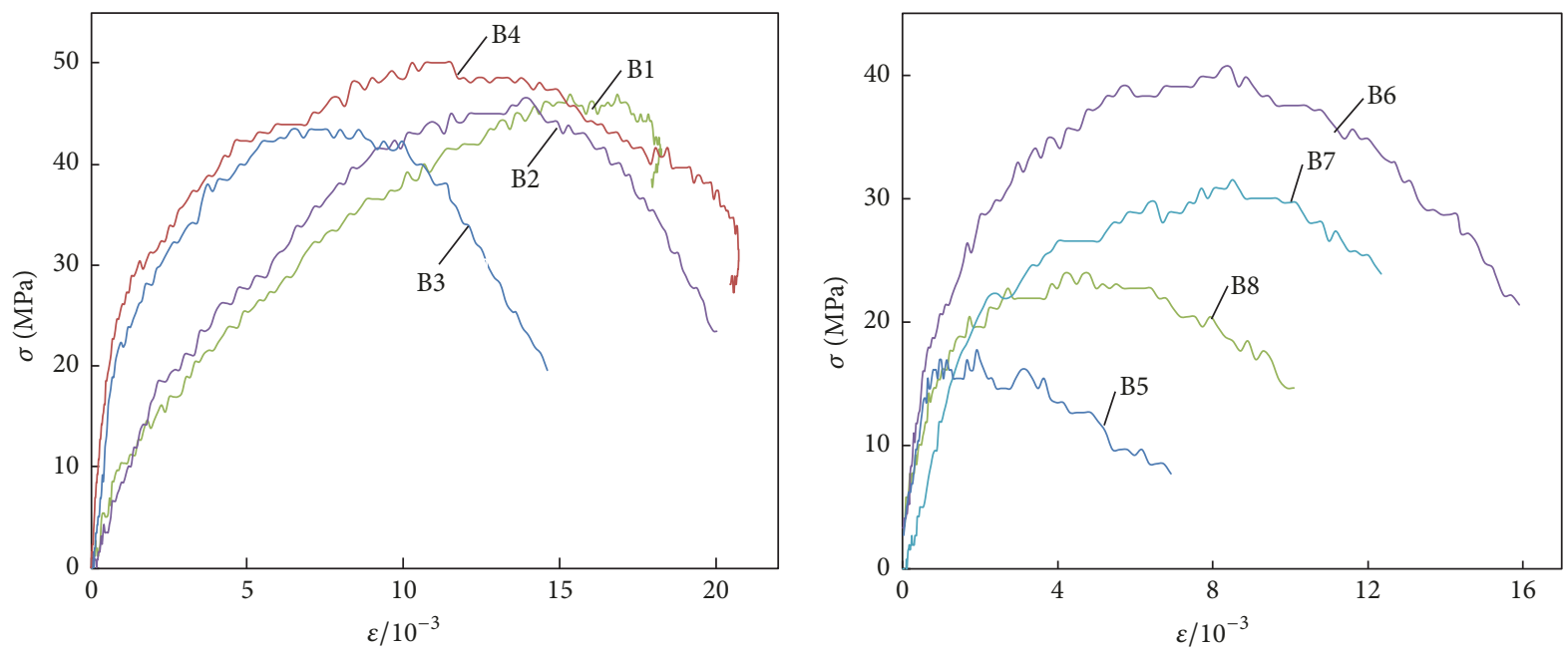

FIGURE 9: Stress-strain curves of natural and 7D saturated specimens in uniaxial static-dynamic loads.
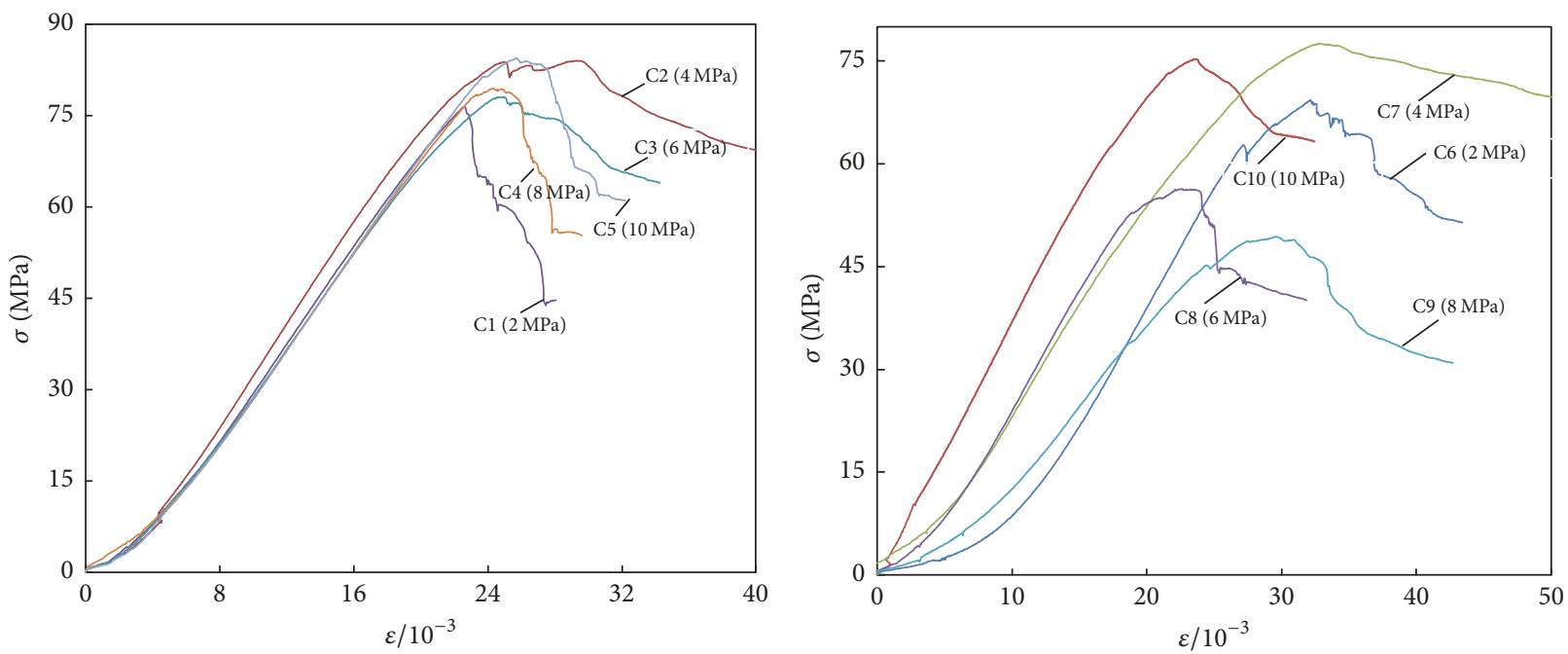

FIGURE 10: Static stress-strain curves of natural and 7D saturated specimens under triaxial compression.

The saturated sandstone dynamic strength is twice as high as the static strength, with a greater improvement than that of coal specimens.

3.3. Results of 3D Static Loading Tests. As illustrated in Figure 10, the static strength of natural specimens under triaxial loading ranges from 76.39 to $84.41 \mathrm{MPa}$, with an average of $81.01 \mathrm{MPa}$ and fluctuation of $10.49 \%$. The static strength of $7 \mathrm{D}$ saturated specimens ranges from 49.39 to $77.54 \mathrm{MPa}$, with an average of $65.54 \mathrm{MPa}$ and fluctuation of to $59.98 \%$, as shown in Table 3 . The softening coefficient of 7D saturated specimens compared to natural specimens is 0.81 .

The deformation behavior of the natural state and 7D saturated specimen stress-strain curves are roughly the same before the peak value, exhibiting impaction, elastic, and yield stages. However, distinct differences are apparent following the peak. The postpeak stress of natural specimens obviously decreases and shows the features of brittle failure, while the postpeak stress of the 7D saturated specimens decreases slowly and exhibits plastic features. As coal contains multivoids and multicracks, under triaxial static loading, the coal strength and deformation behavior are affected by saturation conditions to differing extents, and water has an obvious softening effect on cracked coal specimens.

3.4. Results of 3D Static-Dynamic Loading Tests. Under the 3D loading system with the same dynamic loading and confining pressure, the dynamic strength of the natural and 7D saturated specimens under different axial pressures are obtained when the confining pressure is $4 \mathrm{MPa}$, as shown in Table 4. The dynamic strength of the natural specimens under different axial pressures ( 8 to $36 \mathrm{MPa}$ ) varied from 54.23 to $70.16 \mathrm{MPa}$, as shown in Figure 11. The results demonstrate that the dynamic strength of $20 \mathrm{MPa}$ under axial compression is $39.02 \%$ higher than that of axial compression at $8 \mathrm{MPa}$. The dynamic strength of the 7D saturated specimens under 


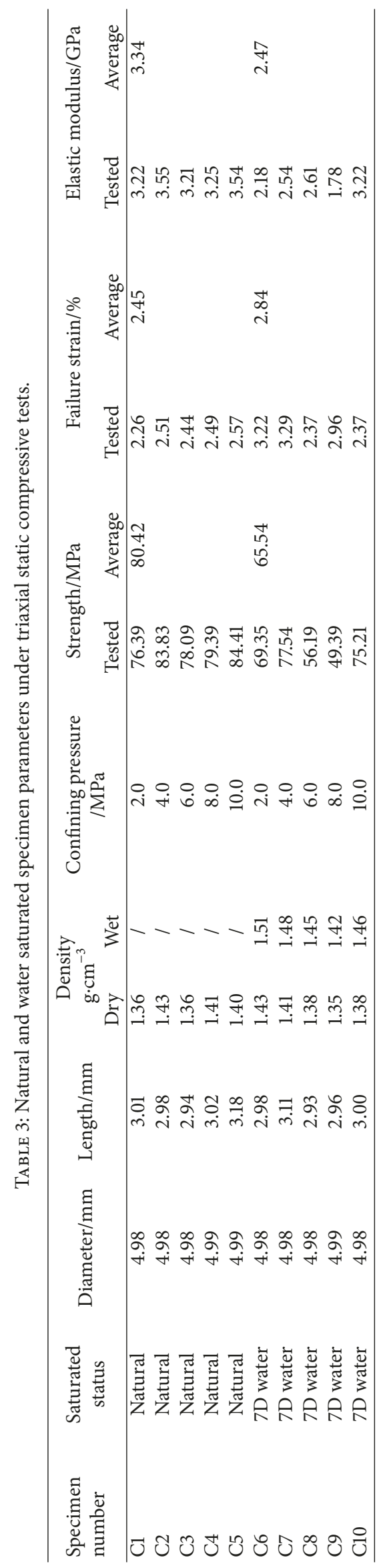




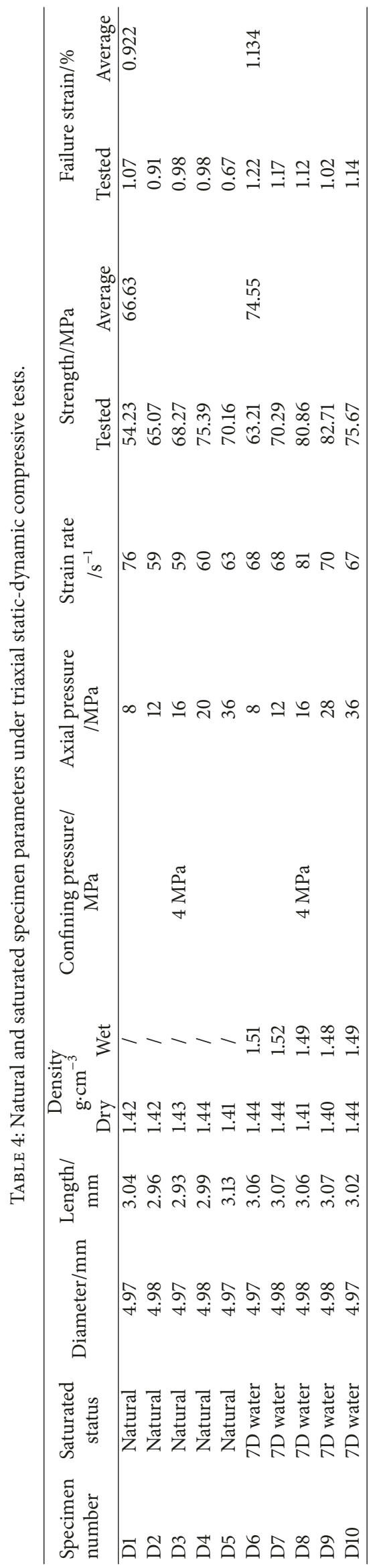



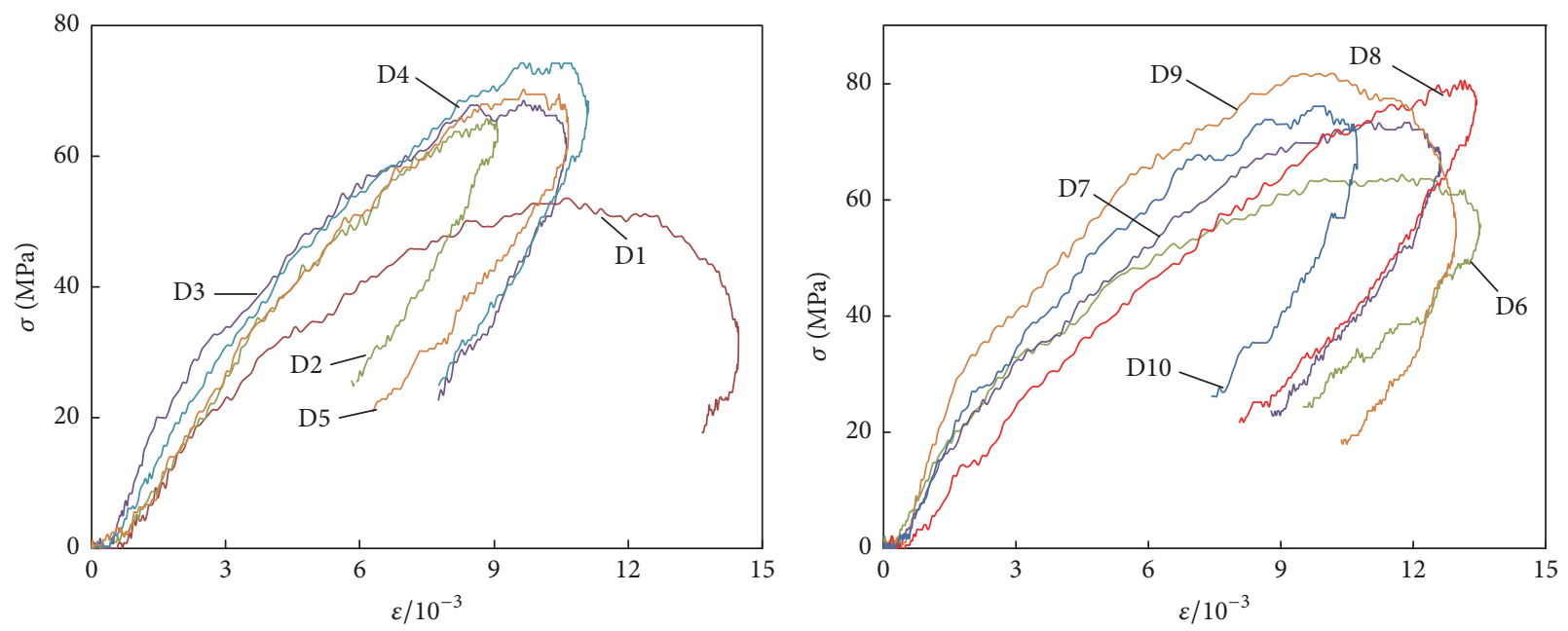

FIGURE 11: Dynamic stress-strain curves of natural and 7D saturated specimens under confining pressure of $4 \mathrm{MPa}$.

different axial pressures ( 8 to $36 \mathrm{MPa}$ ) was 63.21 to $75.67 \mathrm{MPa}$. The 7D saturated specimen test results indicate that the dynamic strength of axial pressure at $28 \mathrm{MPa}$ is $30.85 \%$ higher than that at $8 \mathrm{MPa}$. During the elastic stage, it appears that the specimens subjected to larger axial pressure exhibit greater dynamic strength under the 3D stress condition. Furthermore, the influence of axial pressure on the dynamic strength of the 7D saturated specimens is similar to that of the natural specimens.

Under different axial pressure conditions, the dynamic strength of the specimens first increases and then decreases with an increase in axial pressure. The turning points of the specimen dynamic strengths occur when axial pressure is 20 and $28 \mathrm{MPa}$ (47\% and $66 \%$ of the uniaxial static strength, resp.), and the dynamic strength of the natural and 7D saturated specimens exhibits a decreasing characteristic during the test. The dynamic strength of the saturated 7D specimens is higher than that of the natural specimens by $7.85 \%$ to $18.44 \%$, which indicates that the dynamic strength of $7 \mathrm{D}$ saturated specimens increases compared to that of natural specimens in the 3D static-dynamic tests.

As a porous medium, coal often has a lower compactness than ordinary sandstone and limestone, and numerous irregular fissures and pore exist in the coal seam. When the coal specimen is loaded under axial compression and confining pressure, it remains in the elastic state under 3D compression stress, and it becomes smaller in volume as the fissures and pores are gradually compressed. When the axial pressure increases and the specimen remains in the elastic range, the specimen dynamic strength also increases. The effects of axial compression and confining pressure on the specimen dynamic strength manifest mainly in the elastic range; when the axial pressure increases to the point where specimens show swelling damage, the internal cracks of the coal increase gradually and the dynamic strength decreases.

\section{Broken Characteristics of Natural and Saturated Specimens}

4.1. Broken Characteristics of Specimens in 1D Static-Dynamic Loading. To monitor the failure process of specimens under dynamic loading, a high-speed camera (FASTCAM SA1.1) was employed to capture coal specimens during the SHPB test. Under the condition of $1024 \times 1024$ resolution, the camera can achieve a frame rate of $5400 \mathrm{fps}$, and it can be as high as $675000 \mathrm{fps}$ at the lowest resolution. In this experiment, the frame rate was $100000 \mathrm{fps}$, with pixels at 192 $\times 192$ resolution, and the time space between two adjacent captured photos was approximately $10 \mu \mathrm{s}$. In the $1 \mathrm{D}$ staticdynamic loading tests, both the natural and 7D saturated specimens were photographed, based on which the surface crack propagation characteristics of the specimens were analyzed, and the dynamic failure process of the natural and 7D saturated specimens is discussed in detail.

Figures 12 and 13 illustrate the fracture propagation and failure process of the natural specimen (B2) and 7D saturated specimen (B8), respectively.

When the natural specimen (B2) is impacted in the uniaxial dynamic test, a single crack appears on it at the 200th $\mu$ s. At the 400th and 600th $\mu \mathrm{s}$, the cracks increase significantly and penetrate the entire specimen. At the 800th $\mu$ s, the number of cracks and the crack width gradually increases, accompanied by the appearance of small secondary cracks. The specimen fracture width gradually increases at the 1000th $\mu$ s, and at the 1200th $\mu \mathrm{s}$, the integrity of the specimens changes, and they lose bearing capacity as particles begin to burst out. The period of the specimen fracture from first damaged to total failure lasted for 1200th $\mu \mathrm{s}$, and the specimen fragmentation degree is relatively large.

The 7D saturated specimen (B8) appears obvious cracks at 100 th $\mu$ s. Although numerous cracks penetrate the specimens at the 300 th $\mu$ s, the specimen remains intact; more cracks 

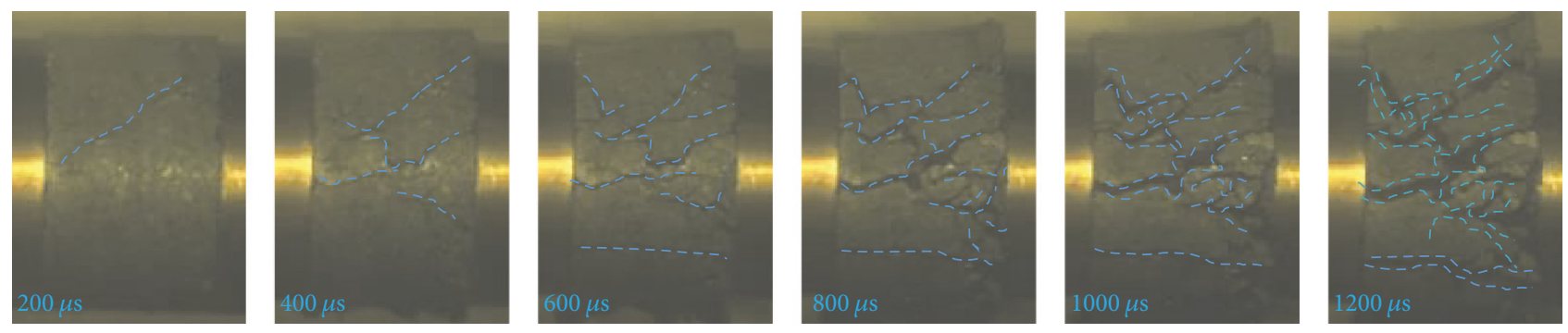

FIGURE 12: High-speed photos of natural specimen (B2) in dynamic failure processing.
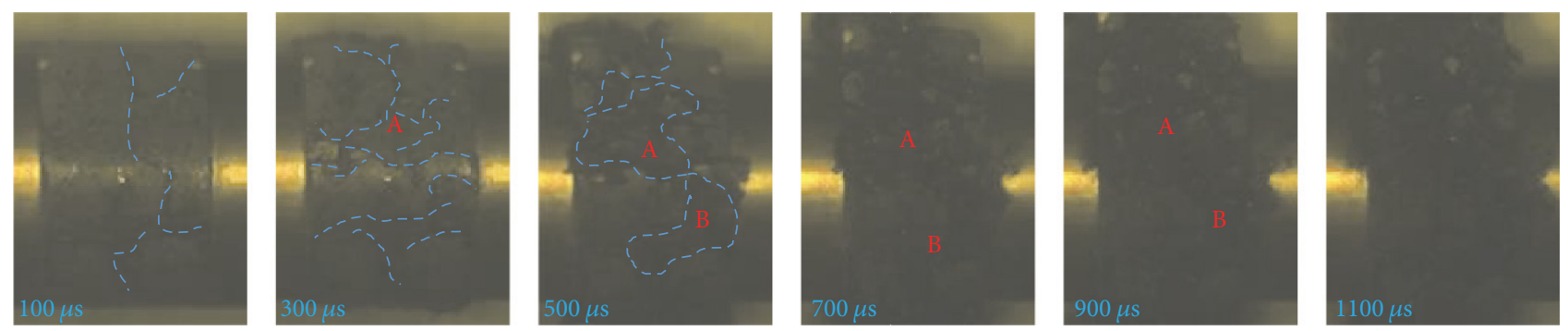

FIGURE 13: High-speed photos of 7D saturated specimen (B8) in dynamic failure processing.

appear at the 500th s, at which point the cracks coalesce with one another. The crack width at areas $\mathrm{A}$ and $\mathrm{B}$ increases gradually, along with serious damage occurring. At the 700 th $\mu$ s, relatively wide cracks appear in areas $\mathrm{A}$ and $\mathrm{B}$, and large coal particles are ejected, with specimen integrity being destroyed. At the 900th and 1100th $\mu$ s, large numbers of particles are ejected and the fragments are relatively small.

Comparing the dynamic failure process of the natural and $7 \mathrm{D}$ saturated specimens, the failure duration of the natural specimens is longer, the fragment is larger, and the specimen integrity is maintained for longer, while the destruction duration of the 7D saturated specimens appears shorter and the destroyed particles are smaller. The reason for this phenomenon is that the coal specimens contain numerous voids, and the voids in the natural specimens contain air, while those in the 7D saturated specimens contain water. The failure process of the natural and saturated 7D specimens was statistically analyzed, demonstrating the failure characteristics of the natural (B2) and 7D saturated (B8) specimens. The water content of the 7D saturated specimen increases and both the voids and cracks contain water. When the static load is applied, the specimen is in the elastic state, and the pores and fractures are compressed. In this case, the fracture is under the compression of the void water pressure.

Under the action of dynamic loading, the stress wave propagates onto the fracture and the water contained therein, and the pore compression deformation is equivalent to the pore water pressure acting on the fracture wall; thus, the failure time of the 7D saturated specimen shortens. Moreover, the saturated water has a weakening effect on the fracture bond, resulting in a decrease in the fracture cohesive force. Therefore, compared to static loading, coal specimen cracks appear to initiate and propagate more easily under the action of a stress wave, and the particle breakage size is smaller.

\subsection{Destroyed Particle Statistics of Natural and 7D Saturated} Specimens. The particle masses following impact were statistically analyzed. The particles were classified into three grades, according to fragment sizes of less than 30,10, and $5 \mathrm{~mm}$. The particles were screened, and the quality of each grade and total quality percentage (\%) were calculated as shown in Table 5.

(1) In the static uniaxial compression test for the natural and 7D saturated specimens, the natural specimen integrity following failure is more obvious, and the average sizes of particles less than $30 \mathrm{~mm}$ range from 26 to $33 \%$ of the total mass in Figure 14. However, the failure degree of the 7D water-saturated specimens became more serious following impact, and the percentage of particles with diameters less than $30 \mathrm{~mm}$ ranges from 39 to $74 \%$ of the total mass.

(2) While testing the natural and 7D saturated specimens under $1 \mathrm{D}$ static-dynamic loading, the average size of the natural specimen broken particles is larger than that of the $7 \mathrm{D}$ saturated specimen, as shown in Figure 15. For the natural coal specimens, the sizes of particles of less than $30 \mathrm{~mm}$ range from 69.6 to $82.5 \%$ of the total mass; for $7 \mathrm{D}$ saturated specimens, the percentage ranges from 83.8 to $94.1 \%$ of the total mass.

(3) In the triaxial static compression test and 3D staticdynamic loading test, the natural and 7D saturated specimen fragment sizes are large, and certain specimens retain the same shape as before testing. In fact, only small size differences exist between the broken particles. It should be noted that, as the specimen is fully confined during the triaxial tests, 
TABLE 5: Quality percentage and fragment sizes of specimens.

\begin{tabular}{lcccccccccccccc}
\hline \multirow{2}{*}{ Size } & A1 & A2 & A3 & A4 & A5 & A6 & $\begin{array}{c}\text { B1 } \\
(\%)\end{array}$ & $\begin{array}{c}\text { B2 } \\
(\%)\end{array}$ & $\begin{array}{c}\text { B3 } \\
(\%)\end{array}$ & $\begin{array}{c}\text { B4 } \\
(\%)\end{array}$ & $\begin{array}{c}\text { B5 } \\
(\%)\end{array}$ & $\begin{array}{c}\text { B6 } \\
(\%)\end{array}$ & $\begin{array}{c}\text { B7 } \\
(\%)\end{array}$ & $\begin{array}{c}\text { B8 } \\
(\%)\end{array}$ \\
\hline$<30 \mathrm{~mm}$ & 33 & 28.5 & 26 & 56 & 39 & 74 & 69 & 74.4 & 69.4 & 82.5 & 90.7 & 94.1 & 84.9 & 83.8 \\
$<10 \mathrm{~mm}$ & 12 & 16 & 8 & 21 & 19 & 33 & 6.9 & 9.1 & 7.5 & 9.8 & 8.9 & 13.1 & 8.7 & 8.2 \\
$<5 \mathrm{~mm}$ & 6.4 & 7.6 & 4.4 & 7.5 & 6.8 & 8 & 3.1 & 3.4 & 4.3 & 4.8 & 6.3 & 9.3 & 8.3 & 5.9 \\
\hline
\end{tabular}
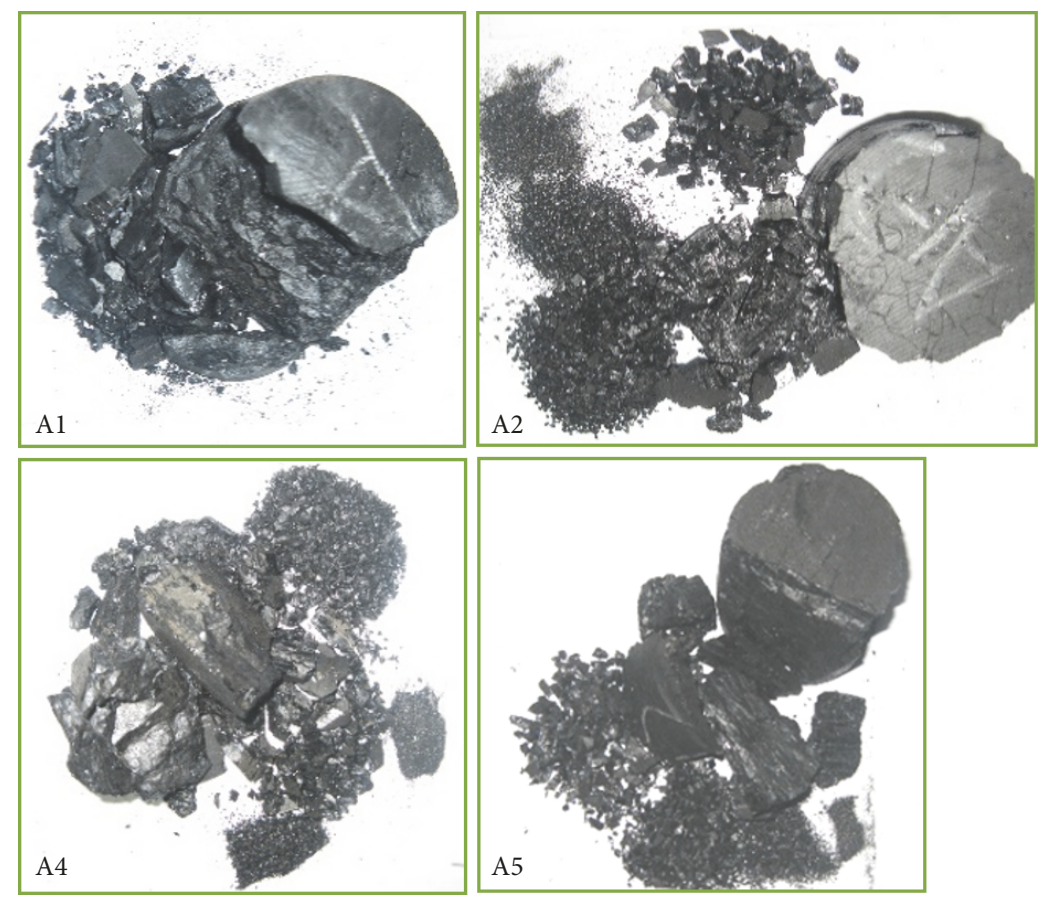
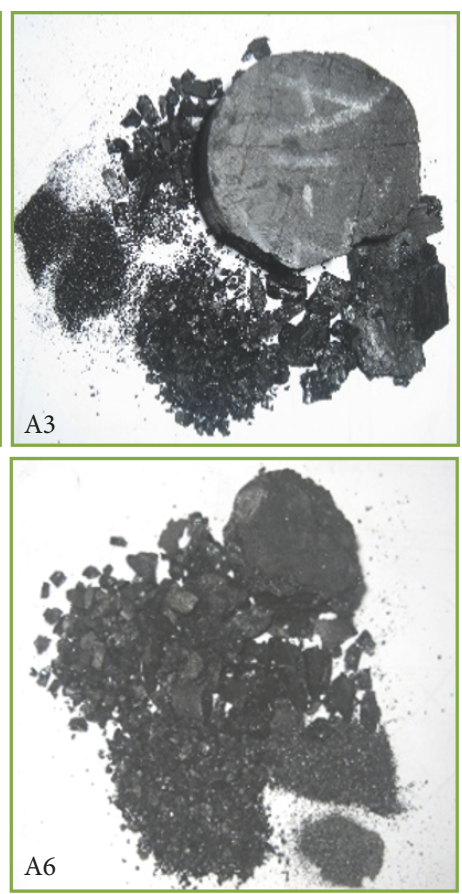

FIGURE 14: Failure forms of natural and 7D saturated specimens under uniaxial static loads.
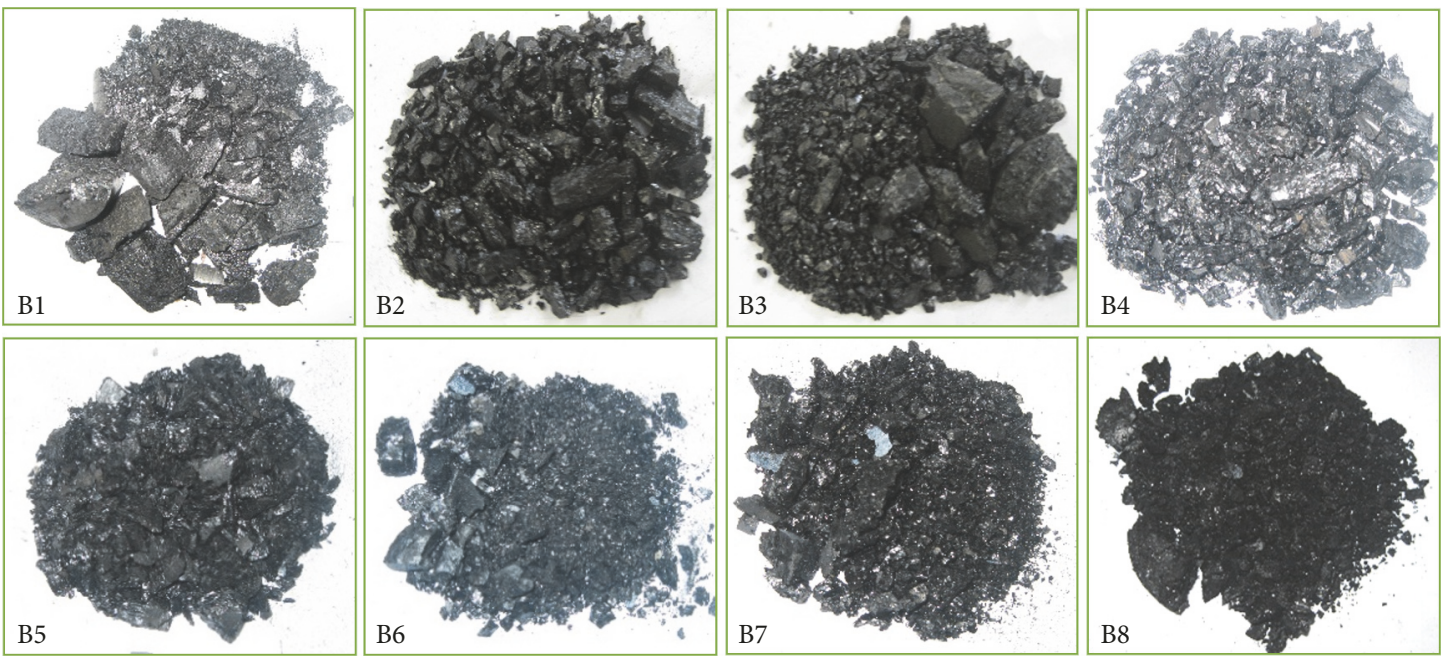

FIGURE 15: Failure forms of natural and 7D saturated specimens under uniaxial static-dynamic loads. 

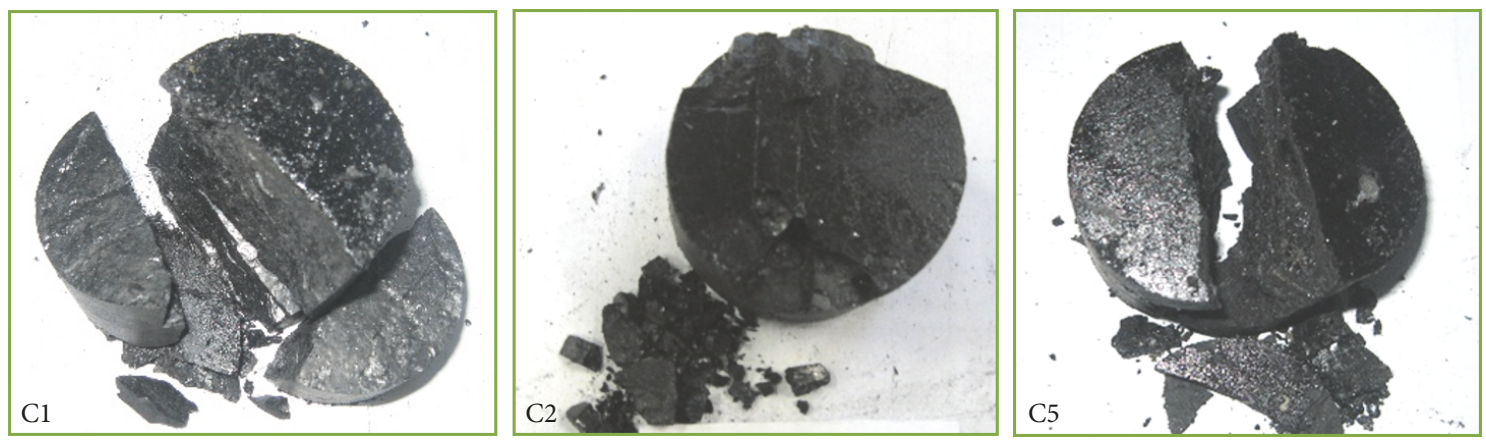

FIGURE 16: Failure forms of natural and water-saturated specimens under triaxial static loads.
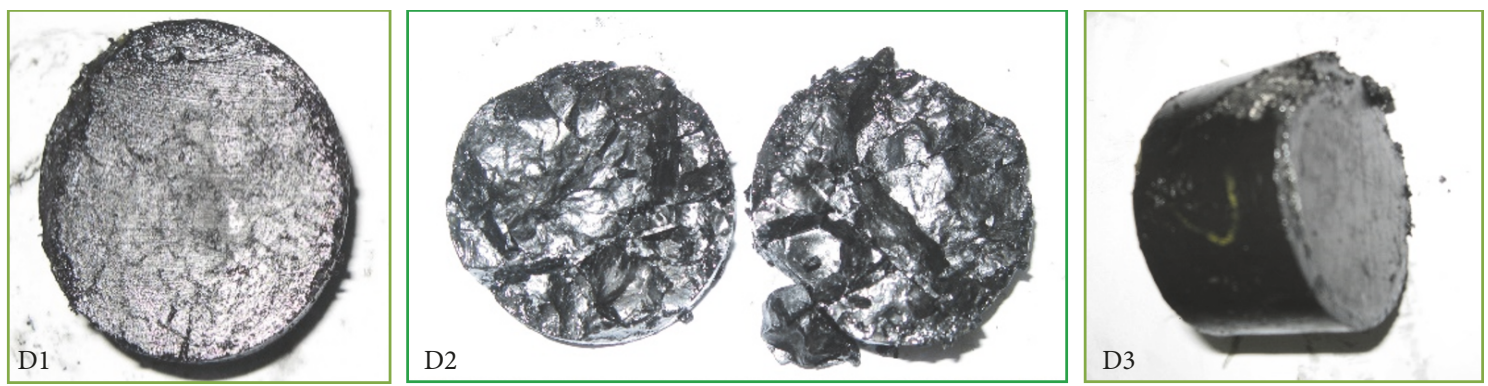

FIGURE 17: Failure forms of natural and water-saturated specimens under triaxial static-dynamic loads.

saturation has little influence on the broken particle sizes, as shown in Figures 16 and 17.

\section{Conclusion}

In this paper, the strength and failure characteristics of natural and water-saturated coal specimens are investigated. Static and static-dynamic loading tests, including uniaxial static and triaxial static loading, $1 \mathrm{D}$ static-dynamic loading, and $3 \mathrm{D}$ static-dynamic loading, are conducted using the RMT150 and SHPB system. The main conclusions are as follows. (1) Under uniaxial compression and the $1 \mathrm{D}$ static-dynamic condition, the 7D saturated specimen strengths are lower than those of the natural specimens. (2) Under the triaxial static condition, the 7D saturated coal specimen strengths are lower than those of the natural specimens; however, in the 3D static-dynamic loading condition, the 7D saturated specimen strengths are higher than those of the natural specimens. (3) Under uniaxial compressional and 1D static-dynamic loading conditions, the broken particle sizes of the $7 \mathrm{D}$ saturated specimens are smaller than those of the natural specimens, indicating that saturation has a significant influence on particle breakage. However, under triaxial and 3D staticdynamic loading, saturation has no obvious influence on the broken particle sizes, due to the confinement effect.

\section{Conflicts of Interest}

The authors declare that there are no conflicts of interest regarding the publication of this paper.

\section{Acknowledgments}

The work is supported by the National Natural Science Foundation of China (51604093 and 51474096), Program for Innovative Research Team at the University of Ministry of Education of China (IRT_16R22), Scientific and Technological Key Project of Henan Province (172107000016), and the Doctoral Research Fund Project of Henan Polytechnic University, China (B2017-42).

\section{References}

[1] L. K. Wei, Q. X. Qi, H. Y. Li et al., "A case study of damage energy analysis and an early warning by microseismic monitoring for large area roof caving in shallow depth seams," Shock and Vibration, vol. 2015, Article ID 709459, 9 pages, 2015.

[2] Z. J. Wen, X. Wang, Y. L. Tan et al., "A study of rockburst hazard evaluation method in coal mine," Shock and Vibration, vol. 2016, Article ID 8740868, 9 pages, 2016.

[3] L. Dong, W. Zou, X. Li, W. Shu, and Z. Wang, "Collaborative localization method using analytical and iterative solutions for microseismic/acoustic emission sources in the rockmass structure for underground mining," Engineering Fracture Mechanics, 2018.

[4] P. A. Hale and A. Shakoor, "A laboratory investigation of the effects of cyclic heating and cooling, wetting and drying, and freezing and thawing on the compressive strength of selected sandstones," Environmental \& Engineering Geoscience, vol. 9, no. 2, pp. 117-130, 2003.

[5] A. Özbek, "Investigation of the effects of wetting-drying and freezing-thawing cycles on some physical and mechanical properties of selected ignimbrites," Bulletin of Engineering Geology and the Environment, vol. 73, no. 2, pp. 595-609, 2014. 
[6] G. Khanlari and Y. Abdilor, "Influence of wet-dry, freeze-thaw, and heat-cool cycles on the physical and mechanical properties of Upper Red sandstones in central Iran," Bulletin of Engineering Geology and the Environment, vol. 74, no. 4, pp. 1287-1300, 2015.

[7] X. R. Liu, Z. J. Wang, Y. Fu, W. Yuan, and L. L. Miao, "Macro/ microtesting and damage and degradation of sandstones under dry-wet cycles," Advances in Materials Science and Engineering, vol. 2016, Article ID 7013032, 16 pages, 2016.

[8] B. Y. Zhang, J. H. Zhang, and G. L. Sun, "Deformation and shear strength of rockfill materials composed of soft siltstones subjected to stress, cyclical drying/wetting and temperature variations," Engineering Geology, vol. 190, pp. 87-97, 2015.

[9] H. C. Yu, Y. Zhao, and H. D. Liu, "Experimental study of influence of water on stress relaxation of rock under triaxial stresses," Chinese Journal of Rock Mechanics and Engineering, vol. 34, no. 2, pp. 313-322, 2015.

[10] X. Li, T. Zhou, D. Li, and Z. Wang, "Experimental and numerical investigations on feasibility and validity of prismatic rock specimen in SHPB," Shock and Vibration, vol. 2016, Article ID 7198980, 13 pages, 2016.

[11] Q. B. Zhang and J. Zhao, "A review of dynamic experimental techniques and mechanical behaviour of rock materials," Rock Mechanics and Rock Engineering, vol. 47, no. 4, pp. 1411-1478, 2014.

[12] S. Huang, K. Xia, F. Yan, and X. Feng, "An experimental study of the rate dependence of tensile strength softening of longyou sandstone," Rock Mechanics and Rock Engineering, vol. 43, no. 6, pp. 677-683, 2010.

[13] P. Yan and R. Q. Ma, "Split Hopkinson pressure bar tests and analysis of coalmine sandstone with various moisture contents," Chinese Journal of Rock Mechanics and Engineering, vol. 34, no. 1, pp. 2888-2893, 2015.

[14] Z. Zhou, X. Cai, W. Cao, X. Li, and C. Xiong, "Influence of water content on mechanical properties of rock in both saturation and drying processes," Rock Mechanics and Rock Engineering, vol. 49, no. 8, pp. 3009-3025, 2016.

[15] Z. Zhou, X. Cai, L. Chen, W. Cao, Y. Zhao, and C. Xiong, "Influence of cyclic wetting and drying on physical and dynamic compressive properties of sandstone," Engineering Geology, vol. 220, pp. 1-12, 2017.

[16] X. S. Liu, Y. L. Tan, and S. C. Hu, "Pattern recognition of signals for the fault-slip type of rock burst in coal mines," Shock and Vibration, vol. 2015, Article ID 806969, 8 pages, 2015.

[17] Y. L. Tan, Y. C. Yin, S. T. Gu et al., "Multi-index monitoring and evaluation 5on rock burst in Yangcheng Mine," Shock and Vibration, vol. 2015, Article ID 624893, 5 pages, 2015.

[18] Y. H. Cheng, J. C. Bai, Y. K. Ma et al., "Control mechanism of rock burst in the floor of roadway driven along next goaf in thick coal seam with large obliquity angle in deep well," Shock and Vibration, vol. 2015, Article ID 750807, 10 pages, 2015.

[19] C. P. Lu, G. J. Liu, H. Y. Wang et al., "Numerical investigation of rockburst effect of shock wave on underground roadway," Shock and Vibration, vol. 2015, Article ID 867582, 10 pages, 2015.

[20] T. Lu, Z. Zhao, and H. Hu, "Improving the gate road development rate and reducing outburst occurrences using the waterjet technique in high gas content outburst-prone soft coal seam," International Journal of Rock Mechanics and Mining Sciences, vol. 48, no. 8, pp. 1271-1282, 2011.

[21] D. Z. Song, E. Y. Wang, Z. T. Liu, X. F. Liu, and R. X. Shen, "Numerical simulation of rock-burst relief and prevention by water-jet cutting," International Journal of Rock Mechanics \& Mining Sciences, vol. 70, pp. 318-331, 2014.
[22] C. D. Su, X. X. Zhai, and X. Z. Wei, "Influence of saturation period on bursting liability indices for coal seam \#2 in Qianqiu coal mine," Chinese Journal of Rock Mechanics and Engineering, vol. 33, no. 2, pp. 235-242, 2014.

[23] H. Li, H. Li, B. Gao, D. Jiang, and J. Feng, "Study of acoustic emission and mechanical characteristics of coal samples under different loading rates," Shock and Vibration, vol. 2015, Article ID 458519, 11 pages, 2015.

[24] J. F. Pan, Y. Ning, and H. Lan, "Water injection methods in coal bed based on experiments of water immersion time effect of Qianqiu coal samples with burst trend," Journal of China Coal Society, vol. 37, no. 1, pp. 19-25, 2012.

[25] Z. F. Liu, T. H. Kang, and W. Lu, "Experiment on water injection affected on mechanics features of coal body," Coal Science \& Technology Magazine, vol. 38, no. 1, pp. 17-19, 2010.

[26] Y. Zhao, S. Liu, Y. Jiang, K. Wang, and Y. Huang, "Dynamic Tensile Strength of Coal under Dry and Saturated Conditions," Rock Mechanics and Rock Engineering, vol. 49, no. 5, pp. 17091720, 2015.

[27] C. E. Fairhurst and J. A. Hudson, "Draft ISRM suggested method for the complete stress-strain curve for intact rock in uniaxial compression, international society for rock mechanics commission on testing methods," International Journal Rock Mechanics and Mining Sciences, vol. 36, no. 3, pp. 281-289, 1999.

[28] X. Li, Z. Zhou, T.-S. Lok, L. Hong, and T. Yin, "Innovative testing technique of rock subjected to coupled static and dynamic loads," International Journal of Rock Mechanics and Mining Sciences, vol. 45, no. 5, pp. 739-748, 2008.

[29] B. Wang, X. B. Li, and T. B. Yin, "Spilt Hopkinson pressure bar (SHPB) experiments on dynamic strength of water-saturated sandstone," Chinese Journal of Rock Mechanics and Engineering, vol. 29, no. 5, pp. 1003-1009, 2010. 


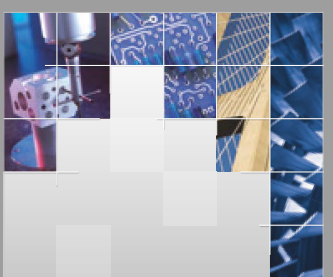

\section{Enfincering}
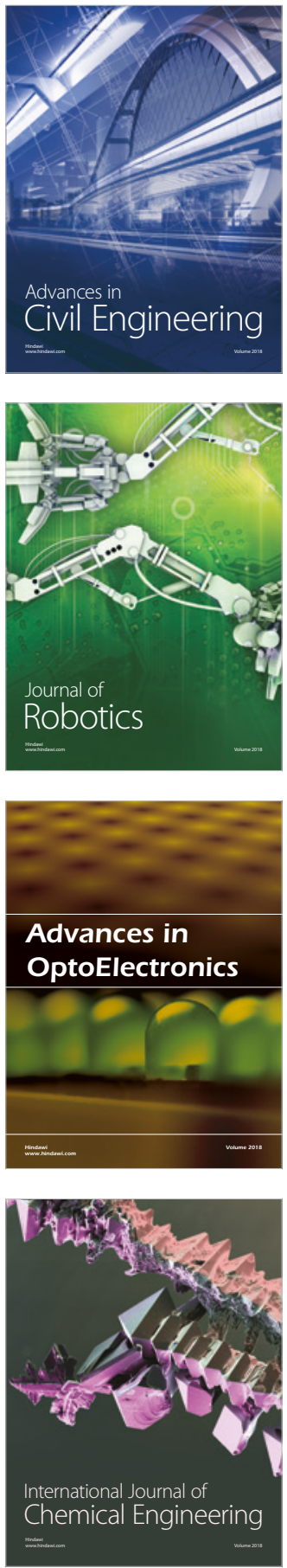

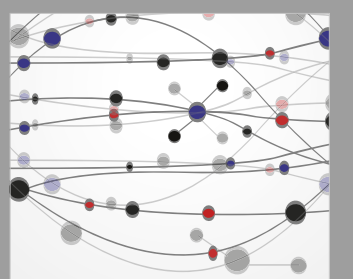

\section{Rotating \\ Machinery}

The Scientific World Journal

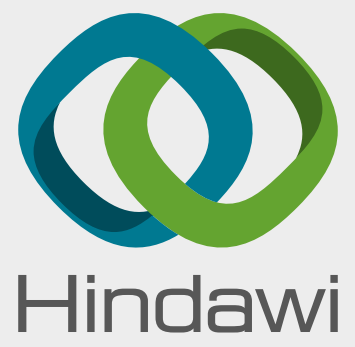

Submit your manuscripts at

www.hindawi.com
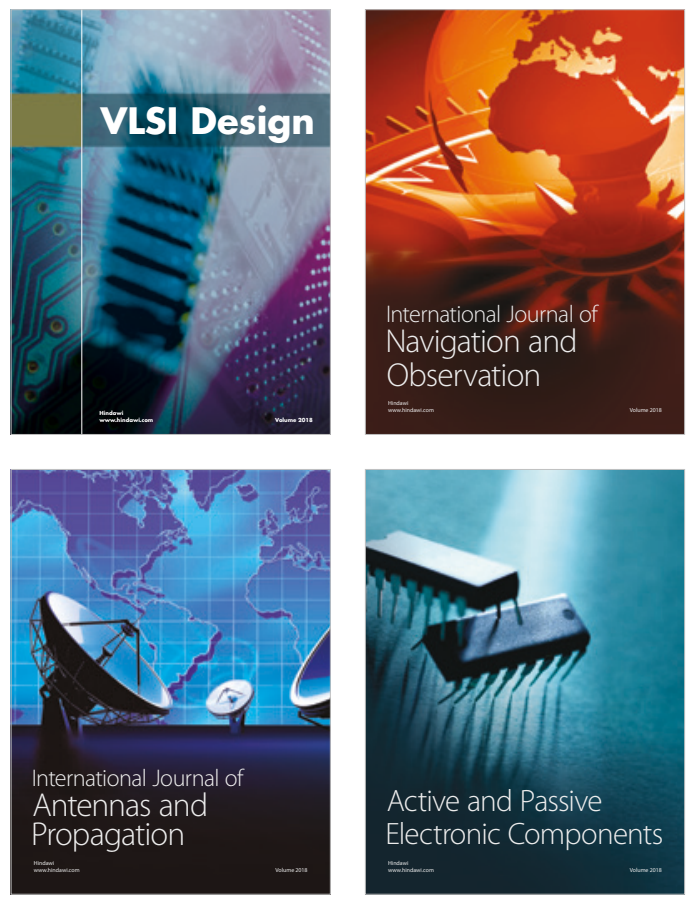
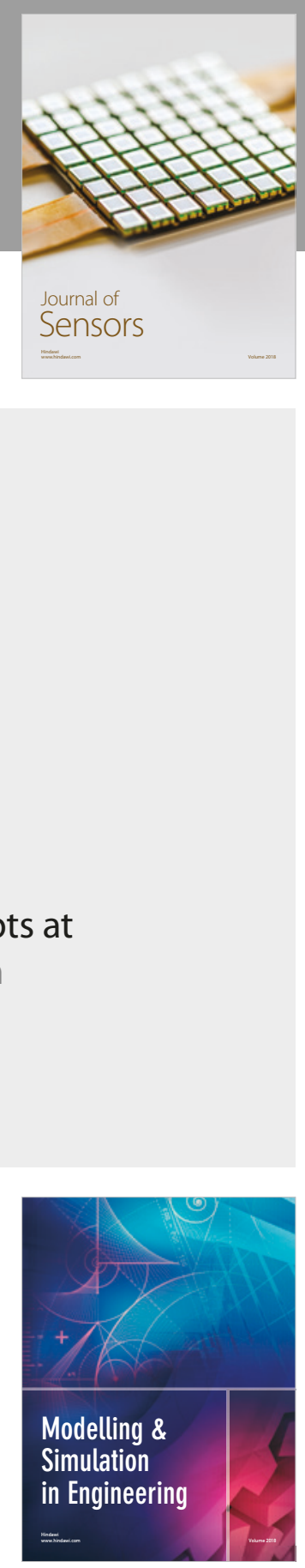

\section{Advances \\ Multimedia}
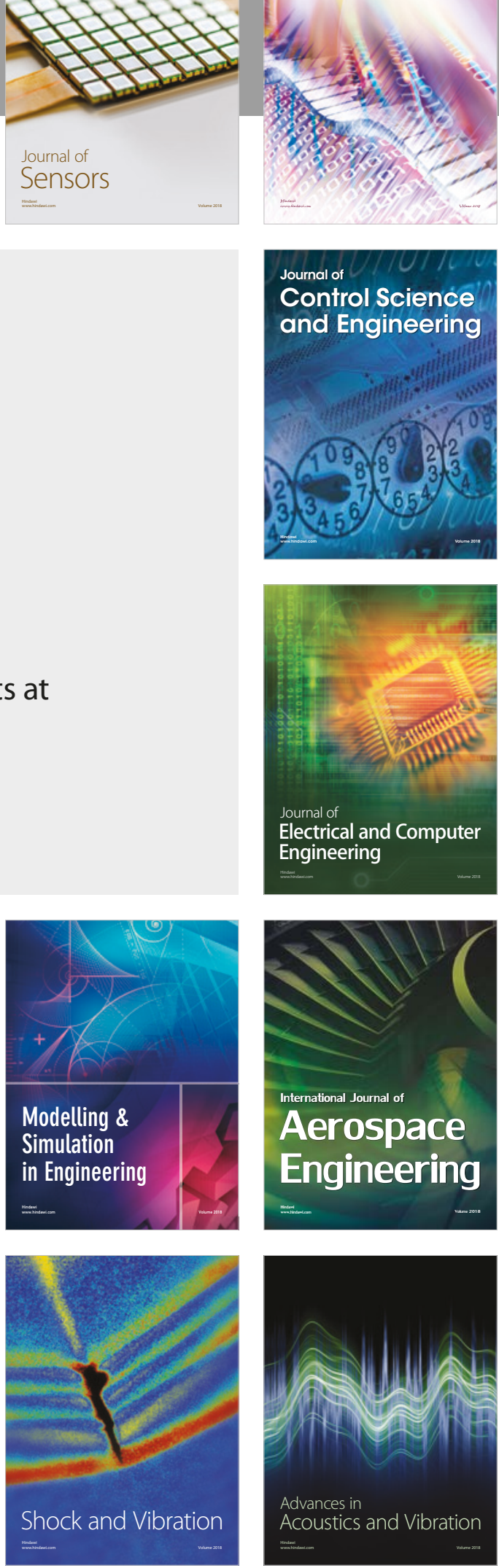